УДК $7.037 .5+7.041+008$

ББК $85.19+71.04+32.816$

DOI: 10.30628/1994-9529-2021-17.2-151-170

received 30.05.2021, accepted 29.06.2021

ДАРЬЯ ОЛЕГОВНА МАРТЫНОВА

Санкт-Петербургская академия художеств имени Ильи Репина, Национальный исследовательский университет ИТМО,

Санкт-Петербург, Россия

Researcher ID: AAK-1891-2020

ORCID: 0000-0003-0426-6458

e-mail: d.o.martynova@gmail.com

\title{
«ЭЛЕКТРИЧЕСКИЙ ПРОТОПЕРФОРМАНС»:
} АВТОМАТ ЭНИГМАРЕЛЬ НА МЕЖДУНАРОДНОЙ ВЫСТАВКЕ СЮРРЕАЛИЗМА 1938 ГОДА ${ }^{1}$

\begin{abstract}
Аннотация. Нижеследующая статья написана по материалам выступления на международной научной конференции «Искусство и машинная цивилизация». В статье проводится анализ публикаций в периодических изданиях начала XX века, связанных с Энигмарель и автоматами, для выявления значения явления Энигмарель на Международной выставке сюрреализма 1938 года. В ходе исследования автор пришел к выводу, что явление Энигмарель было центральным событием открытия, своего рода «вобблером», который должен был привлечь и заинтриговать публику. Энигмарель - это документально подтвержденный курьез начала XX века, мистифицированный в популярных парижских газетах первой половины XX века. Изначально Энигмарель создали лишь для развлечения публики, так как популярность автоматов возобновилась в связи с развившейся во второй половине XIX века кукломанией. Однако в 1938 году для Международной сюрреали-
\end{abstract}

\footnotetext{
${ }^{1}$ Автор выражает благодарность своему научному руководителю - профессору кафедры зарубежного искусства Санкт-Петербургской академии художеств Ю.И. Арутюнян, а также главному научно-творческому коллективу журнала «Наука телевидения» и лично его главному редактору Е.В. Дукову, научному редактору Г.Р. Консону и ответственному секретарю О.Б. Хвоиной за неоценимую помощь в подготовке статьи.
} 
стической выставке в Париже сюрреалисты превратили автомат Энигмарель в выставочный экспонат и сместили акцент с его развлекательной функции на символическую, в результате чего «механический человек» стал образом «идеального» человека, несущего опасность и смерть. Подобной смене интерпретации способствовала истерия, принципиально значимая для творчества сюрреалистов. Также центральное значение Энигмарель можно объяснить ссылкой на связь с Франкенштейном. Автомат предстает как управляемый с помощью электричества механизм, что проводит параллели с практиками месмеризма, во время которых можно было контролировать любое тело с помощью электрического импульса.

В ходе исследования можно прийти к выводу, что сюрреалисты превратили феномен популярной культуры автомата Энигмарель в выставочный экспонат, коррелировавшийся с кинопроизведениями 1920-х-1930-х годов об оживлении и сотворении неживого существа (фильмы «Франкенштейн» 1931 года, «Метрополис» 1927 года, «Голем, как он пришел в мир» 1920 года). Подобное позиционирование было связано с месмеризмом и истерией, связанными с окулярцентризмом и предвоенным настроениям времени сюрреалистов. На основании проведенного анализа публикаций в периодических изданиях, можно предположить, что явление Энигмарель предполагало активную вовлеченность зрителя. Это, в свою очередь, служило своего рода «связующим», объединяющим разрозненные элементы выставки.

Ключевые слова: сюрреализм, автомат, Энигмарель, механизмы в искусстве, протоперформанс, роботы в кино, сюрреалистические выставки, энвайронмент, кукломания, Жорж Мельес, международные выставки сюрреализма, Макс Эрнст, Сальвадор Дали 
UDC 7.037.5 + 7.041+008

LBC $85.19+71.04+32.816$

DARIA O. MARTYNOVA

Russian Academy of Arts, ITMO University,

Saint-Petersburg, Russia

Researcher ID: AAK-1891-2020

ORCID: 0000-0003-0426-6458

e-mail: d.o.martynova@gmail.com

\title{
"ELECTRIC PROTO-PERFORMANCE": ENIGMARELLE THE AUTOMATON AT THE 1938 EXPOSITION INTERNATIONALE DU SURRÉALISME
}

\begin{abstract}
The following article is based on a report presented at the Arts and Machine Civilization International Scientific Conference. The author analyzes publications related to Enigmarelle and automata in periodicals of the early twentieth century in order to identify the significance of Enigmarelle's phenomenon at the 1938 International Exhibition of Surrealism. In the course of the study, it was concluded that Enigmarelle became a centerpiece of the opening, a kind of a wobbler that was intended for attraction and intriguing the public. Enigmarelle is a documented curiosity of the early twentieth century, mystified in popular Parisian newspapers of the first half of the century. Initially, Enigmarelle was created only for the entertainment of the public, as the popularity of automaton resumed in connection with the dollomania in the second half of the 20th century. However, for the 1938 International Exhibition of Surrealism in Paris, the surrealists turned Enigmarelle the automaton into an exhibition object and shifted the emphasis of its function from entertaining to symbolic; as a result, the "mechanical human" became the image of an
\end{abstract}

\footnotetext{
2 I would like to thank my scientific supervisor Julia I. Arutyunyan, Professor of the Foreign Arts Department at the Russian Academy of Arts, Saint Petersburg, as well as The Art and Science of Television journal staff, namely Yevgeny V. Dukov, Editor-in-Chief, Grigoriy R. Konson, Scientific Editor, and Olga B. Khvoina, Executive Secretary, for their much-appreciated assistance in preparing this article.
} 
"ideal" person bringing danger and death. This change in the interpretation was facilitated by the hysteria, which is fundamentally significant for the surrealists' work. Also, Enigmarelle's paramount significance can be explained by a reference to its connection with Frankenstein. The automaton, a mechanism controlled by electricity, drew parallels with mesmeric practices, during which a body could be controlled by electric pulses.

It can be concluded that surrealists turned the popular culture phenomenon, Enigmarelle the automaton, into an exhibit that correlated with the films of the 1920s and 1930s about the revivification and creation of an inanimate being (Frankenstein, 1931, Metropolis, 1927, The Golem: How He came into the World, 1920). Such a presentation was associated with mesmerism and hysteria, which was related to the ocularcentristic concept and surrealists' pre-war mood. Based on the analysis of publications in periodicals, it can be assumed that Enigmarelle's phenomenon anticipated viewers' active involvedness. This, in turn, served as a kind of a binder, uniting the disparate elements of the exhibition.

Keywords: surrealism, Enigmarelle the automaton, mechanisms in art, protoperformance, robots in cinema, surrealist exhibitions, environment, dollomania, Georges Méliès, international exhibitions of surrealism, Max Ernst, Salvador Dali

17 января 1938 года состоялось открытие Международной выставки сюрреализма, которая проходила в галерее изящных искусств под руководством Жоржа Вильденштейна по адресу улица Фобур Сент-Оноре, 140. Эта выставка подвела итог первой волне движения, стала своеобразным прощанием с начальным этапом сюрреализма, последней выставкой сюрреалистов в Европе.

Помимо этого, международная выставка сюрреализма 1938 года стала воплощением новой выставочной концепции, которая стремилась отразить бытование предметов в «сюрреалистической среде»: рассматриваемая коллективная экспозиция была своего рода вербальным посылом, который позволил преодолеть концепцию «белого куба» ${ }^{3}$ и создать протоэнвайронмент ${ }^{4}$, что позволило вовлечь зрителя в созданное

\footnotetext{
${ }^{3}$ Концепция "белого куба» - это выставочная концепция. Ее суть заключается в том, что все экспонаты выставляются на фоне белых стен, чтобы свести к минимуму отвлекающие факторы.

${ }^{4}$ Энвайронмент - это сконструированная среда, основная цель которой - вовлечение зрителя в художественное пространство. Автор вводит термин «протоэнвайронмент» по отношению к Международной выставке сюрреализма 1938 года, так как сюрреалисты пытались вовлечь зрителя в выставочное пространство с помощью разнообразных представлений, экспонатов, инсталляций и декораций.
} 
иммерсивное пространство [18, р. 101; 9, р. 21]. О масштабах и значении выставки свидетельствует состав ее «кураторов»: Марсель Дюшан был генератором и арбитром, который также должен был регулировать конфликты между творцами, Макс Эрнст и Сальвадор Дали - техническими консультантами, Ман Рэй и Вольфганг Паален - оформителями.

Именно Эрнст и Дали, идейно близкие друг другу, отвечали за открытие выставки. Логика вернисажа была тщательно продумана и прописана, соответствуя центральной идее репрезентации расщепленной и подавленной личности. Сохранившееся приглашение на выставку детально повествует о «событиях», которые ожидали пришедших [приглашение опубликовано в: 8, р. 175]. Первое требование, прописанное в пригласительном, было адресовано самим посетителям - вход на выставку предполагал обязательное соблюдение дресс-кода - вечерний наряд. Это был ироничный жест, который контрастировал с алогичным устройством выставки и готовящимися так называемыми «событиями».

При соблюдении правила посетители могли увидеть открытие Андре Бретоном выставки, явление существ-объектов, истерию, освещенный клевер, “Упущенный акт» в исполнении Элен Ванель, связанных петухов, светящиеся скобы, спуск кровати по бокам от гидрофилов, "Самые красивые улицы Парижа», "Дождливое такси» и небо, полное опасностей. И если все эти «события» были лишь текстово упомянуты в приглашении, то одно из них было визуализировано фотографией, напечатанной в центре приглашения. Фотография запечатлела некое идущее по улице человекоподобное существо в нелепом костюме и с монструозной улыбкой под конвоем толпы полицейских. В качестве объяснения под фотографией напечатали: «Подлинный потомок Франкенштейна, автомат Энигмарель, сконструированный в 1900 году американским инженером Айрлендом в полночь в ложных плоти и костях пересечет выставку сюрреализма» [8, p. 175].

Подобные визуализация и текстовая расшифровка готовящегося «события» свидетельствуют, что явление Энигмарель было центральным событием открытия, своего рода «вобблером ${ }^{5}$, который должен был привлечь и заинтриговать публику. Однако, в отличие от перформанса «Упущенный акт» в исполнении французской танцовщицы Элен Ванель (мало-

\footnotetext{
${ }_{5}^{5}$ Вобблер (с англ. «приманка») - рекламный элемент, который своей необычной формой привлекает внимание прохожих. В данной статье слово «вобблер» используется в переносном значении: конструкция Энигмарель привлекала публику словно вобблер.
} 
известный перформанс в контексте сюрреализма), который в последнее десятилетие стал предметом пристального анализа исследовательницы Марии Розы-Леманн (восстановившей его хронологию и нашедшей воспоминания свидетелей действа) [16; 18], про явление Энигмарель на Международной выставке сюрреализма ничего неизвестно.

При описании этого «события» исследователи отталкиваются от пригласительного и опубликованной там информации об Энигмарель, не поднимая архивные источники [напр., 6, р. 52]. Это приводит к аберрациям: часто в текстах Энигмарель называют «автоматоном»", а не «автоматом» 7 [8, p. 175], что диаметрально меняет функциональное назначение механизма; помимо этого, исследователи путают даты появления Энигмарель, указывая либо 1904, либо 1905, либо 1900 года [4, р. 41; 22; 8, р. 246]. Подобные ошибки связаны с иронией визуальности «события»: напечатанная фотография (которая, на самом деле, была искусственно созданным коллажем) создает эффект изученности, «легкости» интерпретации.

Однако подобный видимый акцент на Энигмарель указывает на популярность этого “монстра», на его сформировавшуюся «репутацию» в тот период времени. Это подтверждает статья из парижской газеты Le Figaro, которая перепечатала текст приглашения и сосредоточила внимание на Энигмарель как на «изюминке выставки» [15]. В связи с этой гипотезой основной целью настоящего исследования будет анализ газетных статей начала XX века, связанных с Энигмарель и автоматами, для выявления значения Энигмарель на Международной выставке сюрреализма 1938 года. Стоит отметить, что, работая в цифровом архиве Национальной библиотеки Франции и в коллекции А.Л. Гайота (№ 8) Национальной библиотеки Франции, автору настоящей статьи удалось найти описания Энигмарель лишь в книгах и периодических изданиях первой половины XX века. В итоге лакуны в изучении значения Энигмарель системно эта статья не восполнит, так как автору не удалось обнаружить воспоминания современников об этом событии Международной выставки сюрреализма. В связи с этим открытыми останутся неразрешенными вопросы о восприятии появления Энигмарель приглашенными и участниками выставки, а также реальности этого события (вопрос о фальсификации явления

\footnotetext{
${ }^{6}$ Автоматон - это кукла с механизмом, которая обычно может выполнять только одно действие (имеется в виду русскоязычная академическая традиция).

${ }^{7}$ Автомат - механическое устройство, выполняющее несколько действий без участия человека (имеется в виду русскоязычная академическая традиция).
} 
остается открытым). Однако в статье прослеживается генезис Энигмарель, значение автомата для популярной культуры Франции первой половины XX века, а также будет охарактеризовано значение Энигмарель для Международной выставки сюрреализма 1938 года.

Энигмарель - это документально подтвержденный курьез начала XX века. Впервые упоминание о нем встречается не в журнале «Ученый американец» 1906 года, как указывают некоторые издания [8, р. 176], а во французских журналах 1905-1906 годов [напр., 11]. Так, 16 января 1905 года журнал Gil Blas Illustré пишет о «таинственном персонаже Энигмарель, о котором уже все судачат и который дебютирует сегодня в “Казино Парижа"» [22], а 6 февраля того же года Le XIXe siècle указывает Энигмарель среди других развлечений месяца [23]. Эти вырезки свидетельства того, что "рождение» автомата можно отсчитывать с января 1905 года, а также что этот «таинственный персонаж» за короткое время стал главной "диковинкой» и популярным развлечением Парижа начала XX века.

9 ноября 1906 года журнал Le Radical демистифицирует Энигмарель: «Этот герой был создан немцем Фредериком Айрлендом. Благодаря этому механику популярный "механический человек” может двигать своими конечностями, ходить, ездить на велосипеде и даже писать свое имя на доске» [24]. В этом же году на страницах журнала Le Petit Magasin появляется подробное описание устройства «механического человека»: «Немец Фредерик Айрленд, изобретатель - можно сказать, отец - этого нового механизма, потратил годы непрерывного труда, энергичной работы, чтобы его создать. Достаточно рассказать способы конструирования и функционирования автомата, чтобы каждый выполнил требуемую интеллектуальную и материальную работу по расчетам и настройкам описываемого.

Энигмарель высотой около шести футов, весит сто девяносто восемь фунтов и состоит из трехсот шестидесяти пяти различных частей, подогнанных друг к другу. Его ноги из железа и дерева, а руки из стали и свинца. В движение его приводят семь двигателей, работающих благодаря пружине и электричеству.

Два самых мощных двигателя предназначены для того, чтобы заставить работать нижние конечности описываемого субъекта, короче говоря, чтобы побудить его ходить. Чтобы дать двигателям необходимую им мощность, в Энигмарель установили четырнадцать аккумуляторов по восемьдесят четыре вольта каждый, которые производят две тысячи семьсот ампер в час. Эти аккумуляторы также принуждают автомат к вертикальному положению. 
Вот как работает механизм при ходьбе. Прежде всего, один из двух двигателей, о которых мы только что говорили, толкает левую ногу вперед, это движение завершается, ртуть, служащая проводником электрического тока, падает на рычаг, затем возникает электрический контакт, а другой мотор, аналогичный первому, изменяет вес таким образом, что баланс остается прежним. В этот момент второй мотор толкает правую ногу вперед и повторяет ту же работу, что и с левой ногой. Таким образом, автомат работает шаг за шагом, как настоящий человек.

Каждый раз, когда Энигмарель выходит из машины, которая везет его в театр, зрители аплодируют ему стоя, мы спрашиваем о его здоровье, $и$ каждый узнает, что было у их соседа в желудке в тот день» [цит. по: 2, р. 251].

Это одно из самых подробных описаний Энигмарель в прессе. Остальные журналы упоминают автомат среди многочисленных развлечений, которые увеселительные места предлагают посетителям [см., напр., 5]. Из этих газетных сообщений становится ясно, что сюрреалисты указали ложные сведения в приглашении (скорее всего, чтобы усилить эффект от явления Энигмарель): автомат появился во Франции в начале 1905 года, а не в 1900 году, его конструктором действительно был Фредерик Айрленд, но он был не американцем, а немцем, проживавшим во Франции.

Помимо этого, из анализа газет первой половины XX века стала ясна одна из причин, почему явление Энигмарель - своеобразная «приманка» на Международную выставку сюрреализма: появления механического человека стали большим культурным феноменом, каждое из них почти всегда сопровождалось восторженными газетными публикациями. Из описаний Энигмарель можно сделать вывод, что этот автомат был уникальным: он мог качественно выполнять несколько действий, к нему не были подключены провода, его механизмы не были видны зрителям. В связи с этим вставал вопрос о функционировании и конструкции Энигмарель, так как обычно автомат мог выполнять только одно действие (например, ходить, писать или играть в шахматы).

Ответ на загадку Энигмарель дает книга Гарри Лансона «Все о чревовещании, или чревовещание для всех» 1912 года, которая указывает на колоссальное значение автоматов в XX веке [14]. В этой книге отдельная глава была посвящена разнообразным автоматам с различными функциями: автоматы-дети (например, «неисправимый ребенок» - автомат«страшилка»), автоматы-женщины, автоматы-мужчины, автоматы-жи- 
вотные и т.д. Помимо этого, в книге приводятся разнообразные схемы конструкции кукол, марионеток и автоматов, которые наглядно разъясняют их устройство.

Энигмарель становится предметом пристального интереса со стороны Г. Лансона [14, р. 35-36]. Он анализирует его через призму чревовещания. В части, посвященной знаменитому автомату, Г. Лансон приводит в пример автомат-пианиста, который сам играет и поет, однако, на самом деле, звук исходит от чревовещателя [14, p. 34-35]. После этого Г. Лансон пишет о том, что немец-механик выставил напоказ своего механического «человека-загадку», чьи движения и действия будто были управляемы магом или невидимым контролером в берлинском цирке Бускли. Попутно Лансон объясняет, почему Энигмарель стал ярким феноменом популярной культуры: основные функции автоматов - удивлять и развлекать [об автоматах как феномене популярной культуры и развлечении см.: 4, p. 36-38]. Энигмарель выгодно выделялся среди всех механизмов: он совершал несколько действий подряд. Энигмарель мог ходить, прикуривать, курить, ездить на велосипеде и писать мелом на доске свое имя $[14$, р. 35]. По сути, Энигмарель совмещал в себе несколько автоматов, а его многофункциональность почти приравнивала его к человеку, что и удивляло публику. Наряду с этим Г. Лансон сразу же подробно описал конструкцию Энигмарель и трудности, с которыми столкнулся механик при его создании, раскрывая секрет устройства Энигмарель, что нивелировало некую мистификацию популярного автомата [14, р. 36].

Однако после перечисления трудов и механизма Энигмарель Г. Лансон указывает, что автоматы - это выгодный реквизит для чревовещателя и для его театрального представления. Объяснение этому - перечисленные труды и механизм. Числа, металл, детали, отсутствие признаков жизни - все это свидетельства своего рода «объективности» конструкции, ее «научности», вмешательства рационального в, по крайней мере, двигательную жизнь механического человека.

Сложнейшие механизмы автоматов, дополненные описаниями и схемами, убеждают зрителей во вмешательстве науки в «жизнь» автомата. Если обычно чревовещатель просовывал руку в отверстие деревянной куклы и управлял с помощью педалей и нитей своим реквизитом-медиумом, то теперь чревовещатель мог лишь озвучивать автомат.

Помимо автономности механических людей, большое значение для их популярности имело увлечение гипнозом и месмеризмом. Начиная со 
второй половины XIX века, тела пациентов психиатрических клиник стали ассоциироваться с марионетками, куклами и автоматами. Подобные ассоциации были связаны со сценическим характером сеанса гипноза и магнетизма, который спровоцировал критику этих практик. Бельгийский философ Жозеф Дельбеф написал ряд критических статей по поводу этих «театральных представлений» [цит. по: 21, р. 97, 98]. Он анализировал различные единичные «месмерические спектакли» в контексте «шоу» больницы Сальпетриер. Согласно его исследованиям, пациенты становились управляемыми механизмами под влиянием гипнотизера/магнетизера. Он установил, что они стали жертвами «нейромимезиса», то есть под влиянием внушения могли копировать любые предложенные им телесные проявления, в результате чего становились виртуозными актерами, «марионетками», «автоматами», «манекенами», «лабораторными лягушками», “желанным мясом для экспериментов» и идеальными «лабораторными образцами» [цит. по: 21, р. 99]. Через эту призму больница становилась своего рода театром, который создавал для своих «актеров» «сценарии» и «роли».

Эта «сценарная» концепция главенствовала при репрезентации больных. В предвоенную эпоху понятия «куклы» и «автомата» стали особо популярными, так как позволяли не только создавать иллюзию бессмертности и невозможности получить ранения, но и ощущения контроля и управления. В связи с этим человекоподобный контролируемый механизм обладал большой силой и был чрезвычайно привлекателен для зрителей. Автомат Энигмарель ассоциировался с телом, управляемым месмерическим импульсом. Месмерические практики были известны с конца XVIII века. Их суть заключалась в контроле над телом и разумом пациента с помощью невидимых энергий и электрических импульсов. Автомат Энигмарель управлялся и запускался с помощью электричества, что и позволило провести параллели с месмеризмом, интриговавшим художников своей паранормальностью.

«Оживший» автомат, конвоируемый полицейскими из-за своей «опасности», коррелировался, помимо всего сказанного, с кинообразами управляемых или неподконтрольных человеку гуманоидов и автоматов, от которых исходила очевидная угроза человечеству. Так, параллели можно провести с ранними кинофеериями Жоржа Мельеса, связанными с магнетизмом («Гипнотизер» - утраченный фильм 1897 года и «Ванна Месмера» 1905 года). Например, в «Ванне Месмера» Ж. Мельес снял ак- 
трис как марионеток, подчиненных импульсу магнетизера, в конце приравнивая их к подконтрольным и безэмоциональным статуям. И если в этом фильме Ж. Мельес затрагивает тему механического, неживого человека косвенно, то в кинокартине 1897 года «Гугусс и Автомат» неизвестный Автомат становится главным героем. В фильме был снят клоун, сраженный и пораженный механическими движениями Автомата. Тем самым Ж. Мельес, сам восхищавшийся новыми технологиями, продемонстрировал столкновение одной популярной культуры с другой. Сам фильм стал первой кинолентой, в которой появился робот как один из героев.

В этих фильмах Ж. Мельес демонстрировал свое восхищение перед механическими людьми, которое отвечало пристрастиям конца века. Куклы, марионетки, автоматы становились своего рода симулякрами людей, которых можно было контролировать, что спровоцировало развитие феномена так называемой «мономании кукол» в визуальной культуре. Популярность автоматов (особенно женских) в живописи, фотографии, театре или кино была связана с проблемой дислокации и доступности обнаженного женского тела в визуальной культуре.

Обнаженное феминное тело было невозможно увидеть нигде, кроме как в парижском морге, на столе патологоанатома или в больнице. Безвольные, обездвиженные, управляемые тела становятся источниками своеобразного «знания». Их безжизненность переносится и на женскую образность во второй половине XIX века, спровоцировав проникновение кукол и автоматов в искусство. Так, в 1860-е годы Эдгар Дега написал ироничное полотно под названием «Мужчина и кукла», где главной моделью художника становится женская кукла в платье по последней моде (скорее всего, произведение автобиографично, а черты главного героя списаны с самого Дега). Художник Жан Вебер написал полотно «Человек с куклами» в 1896 году, которое экспонировалось в этом же году в Салоне. В 1899 году появляется роман «Человек с куклами» Жан-Луи Рено, в котором подробно описывается фетишизм кукломана [цит. по: 10]. Примечательно, что в конце романа женщина, влюбившаяся в одержимого куклами, решила сыграть роль автомата, поскольку это был единственный способ влюбить в себя главного героя [цит. по: 10].

Создание Энигмарель хронологически совпало с «кукломанией». Сюрреалисты воспользовались популярностью муляжей, автоматов и протезов, возникшей в связи с травмами и потерями Первой мировой войны, чтобы превратить развлекательную конструкцию первой половины 
XX века в выставочный экспонат. В результате их визуальных манипуляций (создании коллажа, акцента на «электрическое происхождение» Энигмарель) механический человек стал образом «идеального» человека, несущего опасность и смерть. Подобной смене интерпретации способствовал истерический дискурс, принципиально значимый для творчества сюрреалистов. Истерия опиралась на визуальность в постановке симптома. В результате она стала прочно ассоциироваться с окулярцентризмом ${ }^{8}:$ медики-мужчины демонстрировали обнаженные истерические тела в «театре больницы Сальпетриер». Подобные демонстрации способствовали внедрению образа «истерического тела» в искусство второй половины XIX века («истерические тела» можно встретить в произведениях Огюста Родена, Фелисьена Ропса, Сары Бернар и многих других).

Управляемое «бесконтрольное» и «подсознательное» представляло большой интерес для сюрреалистов, в связи с этим многие представители направления обращались к «истерическим телам»: Макс Эрнст и Сальвадор Дали. Учитывая, что одним из технических консультантов был Макс Эрнст, то можно предположить, что автором коллажа на пригласительном Международной выставки 1938 года был именно он. М. Эрнст был заинтригован возможностями механизмов и автоматов, что и отразил в коллажах 1920-х годов [см.: 13]. Он соединял женские тела с частями самолетов или бомб, создавая устойчивые к военным последствиям «механизмы». Можно предположить, что именно из-за такой интерпретации «механизмов» Эрнст и включил Энигмарель в программу открытия Международной выставки сюрреализма 1938 года.

Стоит отметить, что автомат Энигмарель становится композиционным центром фотографии приглашения за счёт выделения светом и четко очерченных контуров. Эти детали указывают на то, что фотография подверглась определенным манипуляциями: фигура автомата Энигмарель была вклеена, то есть перед зрителем представили не фото, а коллаж.

В 30-е годы XX века М. Эрнст достаточно часто прибегал к гелиогравюре, чтобы «нивелировать» швы между склейками при изготовлении коллажей. Помимо этого, М. Эрнст был заинтересован в теме месмеризма, подконтрольного и обездвиженного тела и роботов и автоматов. Это ярко проявилось в роман-коллаже 1934 года «Неделя доброты или

\footnotetext{
8 Под этим определением имеется в виду господство зрения в восприятии человеком какоголибо явления.
} 
Семь смертельных элементов» [7, р. 282-285], где женские тела были позиционированы как главный объект. Этот объект становился источником наслаждения для мужчины-вуайериста. В одном из листов М. Эрнст представил женщину-робота, собранную из разрозненных частей тела и механических элементов, и которая обладала яркой сексуальностью.

Все эти листы связывала истерия. Сквозь призму истерии женщина становилась подконтрольным роботом, управляемым врачом. Истеричка, по концепции Жака Лакана, зависит от контролера, она нуждается в заданных моделях поведения, которые механически повторяет (эта концепция описана в Мастер-схеме Лакана об истерике и господине) [1, с. 31].

Истерия объединила и разрозненные объекты, и залы Международной выставки сюрреализма 1938 года. Все оформление выставки было призвано "устранить» буржуазное спокойствие и напомнить об ужасах Первой мировой войны. «Межвоенная эпоха» породила, по мнению сюрреалистов, «сомнамбул», которые не могли выразить свое подсознательное. Посетители нуждались в магистралях, пробуждающих их ото «сна» и позволяющим им трезво взглянуть на окружающую действительность. Свисающие угольные мешки с потолка, пруд посреди комнаты, кромешная тьма в залах - все это создавало дискомфорт, отчужденность и пробуждало страх. Разрозненные и алогичные элементы собрали воедино представления, устроенные М. Эрнстом и С. Дали.

По отношению к этим сюрреалистическим представлениям на открытиях выставок исследовательница Мария-Роза Леманн ввела в научный оборот термин «перформанс» в ряде своих статей [17; 18, р. 102]. В свою очередь идею о перформансах на открытиях сюрреалистических выставок она заимствует у Элис Маон, которая назвала представление «Упущенный акт» 1938 года прото-хэппенингом [20, р. 54]. Леманн заимствует это слово из исследования Маон, в результате чего происходит реинтерпретация термина «перформанс» по отношению к сюрреалистическим практикам на открытиях выставок.

Вводимый термин "перформанс» Леманн применяет к выступлениям танцоров и актеров на сюрреалистических выставках: «Упущенный акт» (1938), «Молитва о прикосновении» (1947), «Банкет каннибалов» (1959) [17, р. 13]. Она пишет, что эти представления делали зрителя активным соучастником, зритель вовлекался в эту игру, проецируя на тела свой личный опыт [17, р. 14]. Поднимая проблему взгляда как всегда насильственного акта, Леманн приходит к выводу, что сюрреалисты неслу- 
чайно устраивали разнообразные представления: они пытались визуализировать подавленные и скрытые в глубинах психики желания публики. Это обеспечивало своеобразную реинтерпретацию концепции взгляда: вместо насильственного он становился вовлеченным, то есть связанным с визуальным опытом и социальным участием.

Появление Энигмарель, заявленное в программе раньше, чем истерический перформанс Элен Ванель, должно было спровоцировать публику на размышления, высвободить ее бессознательное, акцентировать внимание на витающих проблемах (напомним, что 1938 год - предвоенный, год, когда четко наметились социальные и политические конфронтации). В этом контексте и «явление Энигмарель» может считаться перформансом, однако в настоящей статье автор предпочел ввести определение «протоперформанс»", соединив здесь термины Маон («прото-хэппенинг) и Леманн («перформанс»). Использование подобного терминологического неологизма связано с тем, что термин «перформанс» еще не был введен в разговорную и научную практики в период создания сюрреалистических представлений.

«Протоперформанс» с участием механического человека становился символом предвоенной эпохи, напоминанием об ужасах войны от Сальвадора Дали и Макса Эрнста. Эти два разных мастера объединились и стали техническими консультантами не случайно. Обоих роднил подход к бессознательному и любовь к медицине и психиатрии. С. Дали, как и М. Эрнст, не разделял «поэтическую» концепцию истерии, он считал, что эта болезнь позволит выразить «объективную» составляющую бессознательного ${ }^{10}[25$, р. 10]. В доказательство этого он устроил «протоперформанс» под названием "Упущенный акт», во время которого танцовщица Элен Ванель в трех актах имитировала истерический припадок, взаимодействуя с окружающей средой.

Само название "Упущенный акт» указывает на амбивалентность и нестабильность истерии - болезни-протея. Ее невозможно уловить, за

\footnotetext{
${ }^{9}$ Введение приставки «прото» по отношению к терминологическому обозначению сюрреалистических представлений на открытиях выставки обусловливается авторским стремлением следовать принципу историзма, т.к. сами сюрреалисты не обозначали свои постановки как «перформансы», а относились к ним, скорее, как к спектаклям или своеобразной игре со зрителем.

${ }^{10}$ Таким образом, проходила полемика между двумя разными направлениями сюрреализма (линиями развития сюрреализма Бретона и Дали), вылившаяся в «сюрреалистические войны).
} 
ней невозможно уследить. «Протоперформанс» в исполнении Элен Ванель воссоздавал упущенное развитие «истерического спектакля», его исторические коннотации (связь с оковами психических больных, попытка преодолеть "сдерживание» тела и, наконец, стадия "освобождения» - истерическая арка). По сути, С. Дали показал, к чему приводит сдерживание бессознательного, и что может произойти, если поддаться сдерживаемому. Это коррелировалось с современной сюрреалисту ситуации - предвоенным настроениям и страху, которые не обсуждались, но муссировались в обществе.

Подобная стратегия репрезентации «расщепленной» и искалеченной личности, нуждающейся в сдерживании и отвергающей его, находит параллели в кинематографе. Сомнамбула Чезаре, многократно демонстрируемая доктором, восстает против своего «господина» в фильме «Кабинет доктора Калигари». Стоит отметить, что образ доктора, доминирующего над всем, выступающего трикстером и невидимо контролирующего героев и зрителя на протяжении киноленты, был списан с доктора Шарко, исследователя истерии и «заводчика истеричек» [12, р. 63-64; 24, р. 91]. Обращение к образу Шарко было неслучайным: прославленный доктор, занимавшийся верификацией симптомов истерии с помощью визуальных средств [3, р. 185-186], создавал из своих пациентов обезличенные статуи, которые могли находиться в нечеловеческих условиях (неподвижно стоять, лежать на двух стульях, имитировать припадки) долгое время при помощи гипноза и месмеризма [см. подробнее: 19].

«Явление Энигмарель» взаимодействовало с «Упущенным актом». Если Э. Ванель демонстрировала «освобождение» от разума, то Энигмарель, напротив, стал свидетельством «военной» цивилизации и контроля. У «механического человека» нет чувств: он не испытывает боли, любви, сострадания, но при этом он подконтролен, что делает его идеальным военным. Конвоируемый полицейскими Энигмарель предстает как солдат, предвещая будущую катастрофу.

Помимо этого, центральное значение Энигмарель можно объяснить ссылкой на связь с Франкенштейном. Автомат предстает как управляемый с помощью электричества механизм, что, как было отмечено ранее, проводит параллели с практиками месмеризма, во время которых можно было контролировать любое тело с помощью электрического импульса (это ярко продемонстрировано в коллаже Макса Эрнста «Приготовление костного клея» 1921 года). 
Главное проявление контроля - рождение. «Жизнь» Энигмарель зависела от электричества, которое подавалось человеком. В этом контексте на выставке произошла демонстрация «сотворения» "неживого существа», оживление инертного тела, которые волновали умы со времен Фомы Аквинского (первое появление автомата связано с учителем Фомы Аквинского Альбертом Великим [14, р. 30]).

Подобная сцена дублировала популярные образы кинематографа оживление существа в лаборатории доктора в фильме «Франкенштейн» 1931 года, попытка превратить Марию в машину ученого Ротванга в «Метрополисе» 1927 года, а особенно - «неоформленное тело» Голема из фильма «Голем, как он пришел в мир» 1920 года.

Таким образом, использовав феномен популярной культуры - мистифицированный механический человек Энигмарель - сюрреалисты превратили его появление на выставке в форму «протоперформанса», которая коррелировала с кинопроизведениями 1920-х-1930-х годов об оживлении и сотворении неживого существа. Подобное позиционирование было связано с месмеризмом и истерией, связанными с окулярцентризмом и предвоенным настроениям времени сюрреалистов. На основании проведенного анализа публикаций в периодических изданиях, можно предположить, что явление Энигмарель было своего рода явлением «искусства взаимодействия» и предполагало активную вовлеченность зрителя. Это, в свою очередь, служило своего рода “связующим», объединяющим разрозненные элементы выставки.

\section{ЛИТЕРАТУРА}

1. Лакан Ж. Семинары / в ред. Жака-Алэна Миллера; пер. с фр.: М. Титовой, А. Черноглазова. М.: Гнозис, 2008. Кн. 17: Изнанка психоанализа (1969-1970). 272 с.

2. A.B. Mannequins Vivant // Le Prestidigitateur: gazette mensuelle des artistes professionnels et amateurs. 1921. 1 janvier. P. 250-251.

3. Bougousslavsky J., Boller F. Jean-Martin Charcot and art: Relationship of the "founder of neurology" with various aspects of art // Progress in Brain Research. 2013. Vol. 203: The Fine Arts, Neurology, and Neuroscience - Neuro-Historical Dimensions / ed. by S. Finger, D.W. Zaidel, F. Boller, J. Bogousslavsky. Part 2. Chapter 7. P. 185-199. DOI: https://doi.org/10.1016/B978-0-444-62730-8.00007-4.

4. Carper S. Robots in American popular culture. Jefferson, North Carolina: McFarland, 2019. $301 \mathrm{p}$.

5. Chaumont C. Instantané // Le Figaro. 1905. 14 janvier. P. 1.

6. Cottrill J.A. Fortuitous Encounters: Mapping the Museum of Jurassic 
Technology's Surrealist Sensibility. London, Ontario: University of Western Ontario, 1999. $161 \mathrm{p}$.

7. Hornstein K. The Lion of Belfort, Max Ernst's Une semaine debonte, and the Uses of the Past // Nineteenth-Century French Studies. 2021. Vol. 49. № 3-4. P. 282304. DOI: https://doi.org/10.1016/B978-0-444-62730-8.00007-4.

8. Housefield J. Playing with earth and sky: astronomy, geography, and the art of Marcel Duchamp. Hanover, New Hampshire: Dartmouth College Press, 2016. 280 p.

9. Hugnet G. Pleins\&Déliés. Souvenirs et témoignages 1926-1972. Paris: Guy Authier, 1972. $426 \mathrm{p}$.

10. Véber J. The doll man // Sotheby's: site. URL: https://www.sothebys.com/en/ auctions/ecatalogue/2019/tableaux-sculptures-dessins-anciens-pf1909/lot.186.html (дата обращения: 27.05.2021).

11. Jousselin A. Notes du Liseur // Le radical. 1906. 9 novembre. P. 3.

12. Kaes A. Shell Shock Cinema: Weimar Culture and the Wounds of War. Princeton: Princeton University Press, 2009. 328 p.

13. Kavky S. Max Ernst's Post-World War I Studies in Hysteria // The Space Between-Literature and Culture, 1914-1945. 2012. Vol. 8. № 1. P. 37-63.

14. Lançon $\mathrm{H}$. Tous ventriloques, ou La ventriloquie à la portée de tous. Paris: Collection A.-L. Guyot, 1912. 144 p.

15. Le Masque de fer. Les Echos // Le Figaro. 1938. 16 janvier. P. 2.

16. Lehmann M.-R. L'Acte manqué (1938): Le surréalisme entre folie et performance-Un corps placé sous le signe de I'hystérie // Acta lassyensia Comparationis. 2016. № 17. P. 47-56. URL: http://literaturacomparata.ro/Site_Acta/ issues/aic-17/AIC_17_FULL.pdf (дата обращения: 27.05.2021).

17. Lehmann M.-R. La "Voyeurisation" du public dans la performance surréaliste a l'exemple de "L’Acte manqué" (1938), "Prière de Toucher" (1947) et "Banquet cannibale" (1959)—unekampfansageà la morale sociale // Symbolon. 2015. Vol. 16. № 2 (29). P. 13-22.

18. Lehmann M.R. The 1938 Exposition internationale du surréalisme and Acte manqué: The Terror of Memory and the Terror to Come // Lingua Romana. 2017. Vol. 13. № 1. P. 99-112. URL: https://linguaromana.byu.edu/2018/09/04/the-1938exposition-internationale-du-surrealisme-and-acte-manque-the-terror-of-memoryand-the-terror-to-come/ (дата обращения: 27.05.2021).

19. Levingston S. Little demon in the city of light: A true story of murder and mesmerism in Belle Epoque Paris. New York: Knopf Doubleday Publishing Group, 2014. $352 \mathrm{p}$.

20. Mahon A. Surrealism and the Politics of Eros, 1938-1968. London: Thames \& Hudson, 2005. 240 p.

21. Mayer A. Sites of the Unconscious: Hypnosis and the Emergence of the Psychoanalytic Setting. Chicago: University of Chicago Press, 2013. 272 p. 
22. Mortier P. Spectacles et Concerts // Gil Blas. 1905. 16 janvier. N. p.

23. Petit Courrier // Le XIXe siècle: journal quotidien politique et littéraire. 1905. 6 fevrier. N. p.

24. Sacchi D., Belingheri M., Mazzagatti R., Zampetti P., Riva M.A. "The Cabinet of Dr. Caligari": The Scientific Debate on Hypnosis and its Legal Implications between the 19th and the 20th Century // European Neurology. 2020. Vol. 83. № 1. P. 91-96. DOI: https://doi.org/10.1159/000507192.

25. Stent D. Dali / Duchamp in light of Edward James-The International Surrealist Exhibition 1936 // Avant-garde Studies. 2018. № 3. P. 1-29.

\section{REFERENCES}

1. Lacan J. Iznanka psihoanaliza: Kniga 17 (1969-1970) [The other side of psychoanalysis: Book 17, 1969-1970]. Moscow: Gnozis, 2008. 272 p.

2. A.B. Mannequins Vivant. Le Prestidigitateur: gazette mensuelle des artistes professionnels et amateurs. 1 janvier 1921, pp. 250-251.

3. Bougousslavsky J., \& Boller F. Jean-Martin Charcot and art: Relationship of the "founder of neurology" with various aspects of art. In S. Finger, D.W. Zaidel, F. Boller, \& J. Bogousslavsky (Eds.), Progress in Brain Research (Vol. 203, pp. 185-189). 2013. https:// doi.org/10.1016/B978-0-444-62730-8.00007-4

4. Carper S. Robots in American popular culture. Jefferson, North Carolina: McFarland, 2019. 301 p.

5. Chaumont C. Instantané. Le Figaro. 14 janvier 1905, p. 1

6. Cottrill J. A. Fortuitous encounters: Mapping the Museum of Jurassic Technology's surrealist sensibility. London, Ontario: The University of Western Ontario, 1999. $161 \mathrm{p}$.

7. Hornstein K. The Lion of Belfort, Max Ernst's Une semaine de bonte, and the Uses of the Past. Nineteenth-Century French Studies. 2021. 3-4 (49), pp. 282-234. https://doi.org/10.1353/ncf.2021.0010

8. Housefield J. Playing with earth and sky: Astronomy, geography, and the art of Marcel Duchamp. Hanover, New Hampshire: Dartmouth College Press, 2016. 280 p.

9. Hugnet G. Pleins \& Déliés. Souvenirs et témoignages 1926-1972. Paris: Guy Authier, 1972. 426 p.

10. Jean Véber. The Doll Man. Sotheby's. https://www.sothebys.com/en/ auctions/ecatalogue/2019/tableaux-sculptures-dessins-anciens-pf1909/lot.186.html (accessed 27.05.2021)

11. Jousselin A. Notes du Liseur. Le radical. 9 novembre 1906, pp. 3.

12. Kaes A. Shell shock cinema: Weimar culture and the wounds of war. Princeton: Princeton University Press, 2009. 328 p.

13. Kavky S. Max Ernst's Post-World War I studies in hysteria. The Space Between. 2012. VIII (1), pp. 37-63. 
14. Lançon $\mathrm{H}$. Tous ventriloques, ou La ventriloquie à la portée de tous. Paris: Collection A.-L. Guyot, 1912. 144 p.

15. Le Masque de fer. Les Echos. Le Figaro. 16 janvier 1938, p. 2.

16. Lehmann M.-R. L'Acte manqué (1938): Le surréalisme entre folie et performance-Un corps placé sous le signe de I'hystérie. Folie/Madness. 2016. (17), pp. 47-56. http://literaturacomparata.ro/Site_Acta/issues/aic-17/AIC_17_FULL.pdf (accessed 27.05.2021)

17. Lehmann M.-R. La "Voyeurisation" du public dans la performance surréaliste a l'exemple de "L’Acte manqué" (1938), "Prière de Toucher" (1947) et "Banquet cannibale" (1959)-une kampfansage à la morale sociale. Symbolon. XVI (29), pp. 13-22.

18. Lehmann M.-R. The 1938 Exposition internationale du surréalisme and Acte manqué: The terror of memory and the terror to come. Lingua Romana. 2018. (1), pp. 99-112. https://linguaromana.byu.edu/2018/09/04/the-1938-expositioninternationale-du-surrealisme-and-acte-manque-the-terror-of-memory-and-theterror-to-come/ (accessed 27.05.2021)

19. Levingston S. Little demon in the city of light: A True story of murder and mesmerism in belle epoque Paris. New York: Knopf Doubleday Publishing Group, 2014. $352 \mathrm{p}$.

20. Mahon A. Surrealism and the politics of Eros, 1938-1968. London: Thames \& Hudson, 2005. 240 p.

21. Mayer A. Sites of the unconscious: Hypnosis and the emergence of the psychoanalytic setting. Chicago: University of Chicago Press, 2013. 272 p.

22. Mortier P. Spectacles et Concerts. Gil Blas. 16 janvier 1905. N. p.

23. Petit Courrier. Le XIXe siècle: journal quotidien politique et littéraire. 6 fevrier 1905. N. p.

24. Sacchi D., Belingheri M., Mazzagatti R., Zampetti P., \& Riva M. A. "The cabinet of Dr. Caligari": The scientific debate on hypnosis and its legal implications between the 19th and the 20th century. Eur Neurol. 2020. Issue 83 (1), pp. 91-96. https://doi. org/10.1159/000507192

25. Stent D. Dali / Duchamp in light of Edward James-The International Surrealist Exhibition 1936. Avant-garde Studies. 2018. (3), pp. 1-29. 


\section{СВЕДЕНИЯ ОБ АВТОРЕ}

\section{ДАРЬЯ ОЛЕГОВНА МАРТЫНОВА}

аспирант кафедры зарубежного искусства,

ассистент Центра социальных и гуманитарных знаний,

Санкт-Петербургская академия художеств

имени Ильи Репина (СПбАХ),

199034, Санкт-Петербург, Университетская наб., 17,

Национальный исследовательский университет ИТМО (НИУ ИТМО), 197101, Санкт-Петербург, Кронверкский пр., 49

Researcher ID: AAK-1891-2020

ORCID: 0000-0003-0426-6458

e-mail: d.o.martynova@gmail.com

ABOUT THE AUTHOR

DARIA O. MARTYNOVA

PhD student in Art Studies,

Assistant at the Center for Social and Human Sciences,

Russian Academy of Arts,

Universitetskaya nab., 17, 199034,

Saint Petersburg ITMO University,

Kronverkskiy pr., 49, 197101, Saint Petersburg

Researcher ID: AAK-1891-2020

ORCID: 0000-0003-0426-6458

e-mail: d.o.martynova@gmail.com 